\title{
Effect of target power on the physical properties of Ti thin films prepared by DC magnetron sputtering with supported discharge
}

\author{
A. KAVItha ${ }^{1, *}$, R. KAnNAN ${ }^{1}$, S. RAJASHABALA $^{2}$ \\ ${ }^{1}$ Department of Physics, University College of Engineering, Anna University, Dindigul, TamilNadu, 624 622, India \\ ${ }^{2}$ School of Physics, Madurai Kamaraj University, Madurai, Tamil Nadu 625 021, India
}

\begin{abstract}
The present paper describes the effect of target power on the properties of Ti thin films prepared by DC magnetron sputtering with (triode mode) and without (diode mode) supported discharge. The traditional diode magnetron sputtering with an addition of a hot filament has been used to sustain the discharge at a lower pressure. The effect of target power (60, 80, 100 and 120 W) on the physical properties of Ti thin films has been studied in diode and triode modes. XRD studies showed that the Ti thin films prepared at a target power up to $100 \mathrm{~W}$ in diode mode were amorphous in nature. The Ti thin films exhibited crystalline structure at much lower target power of $80 \mathrm{~W}$ with a preferred orientation along $\left(\begin{array}{lll}0 & 0 & 2\end{array}\right)$ plane. The grain size of Ti thin films prepared in triode mode increased from $64 \mathrm{~nm}$ to $80 \mathrm{~nm}$, whereas in diode mode, the grain size increased from $2 \mathrm{~nm}$ to $5 \mathrm{~nm}$. EDAX analysis confirmed that the incorporation of reactive gases was lower in triode mode compared to diode mode. The electrical resistivity of Ti thin films deposited in diode mode was found to be $85 \mu \Omega \cdot \mathrm{cm}$ (target power $120 \mathrm{~W}$ ). The electrical resistivity of Ti thin films in triode mode was found to be deceased to $15.2 \mu \Omega \cdot \mathrm{cm}$ (target power $120 \mathrm{~W}$ ).
\end{abstract}

Keywords: Ti thin films; supported discharge/triode mode; DC magnetron sputtering; target power

(C) Wroclaw University of Science and Technology.

\section{Introduction}

Recently, many researchers are working on improving the physical properties of materials which can be used in numerous applications. For many industrial applications, material property is an important criterion. The structural and microstructural properties of the films are influenced by deposition technique as well as processing parameters such as working pressure, deposition rate, energy of the arrival atoms, substrate temperature, etc. By lowering the working pressure, the mean free path of the atoms/molecules can be increased which, in turn, leads to less loss of energy of the arrival atoms due to reduced number of collisions. This will influence surface morphology and crystalline structure of the deposited film [1]. The increasing substrate temperature results in an increase in the kinetic energy of adatoms, and high film density [2]. By exposing

*E-mail: kavithasep.venkatesan@gmail.com the growing films to energetic particles (ions/fast neutrals) before and during deposition, adhesion and packing density can be increased. The ion bombardment can be accomplished by applying negative bias voltage to the substrate [3,4]. Microscale transition-metal thin films have been developed by many researchers using PVD techniques, such as vacuum arc evaporation [5, 6], cathode arc [7], reactive sputtering [8-10] and ion plating [11, 12], etc. Out of these deposition techniques, sputtering was modified with supported discharge/triode magnetron sputtering. DC sputtering method with supported discharge gives high purity, good adhesion and high deposition rates due to lower operation pressure even at room temperature deposition, controlled deposition rates and crystalline structure in nanoscale. Several researchers have done research in triode magnetron sputtering by biasing the substrate, and at a higher substrate temperature to achieve the required stoichiometry, structure and physical properties of deposited layers [13-16]. 
In the present work, an existing DC magnetron sputtering system has been modified to operate at lower working pressure (argon) by incorporating a thermionic filament which was negatively biased. With the help of the discharge sustained by this assembly, argon pressure of operation could be significantly reduced from $3 \mathrm{~Pa}$ to $0.7 \mathrm{~Pa}$. Due to this independent discharge it was possible to control pressure of operation, target voltage and current, independently. The effect of discharge current caused by the thermionic filament on the target has been studied at various target voltages. The main objective of the present work was to prepare Ti films in standard DC magnetron sputtering and in supported discharge at room temperature, without biasing and compare the structural properties of the deposited films.

\section{Experimental}

The DC magnetron sputtering system having supported discharge (triode) assembly is shown in Fig. 1a. It consists of water cooled cylindrical chamber of $40 \mathrm{~cm}$ diameter and $40 \mathrm{~cm}$ height. A $50 \mathrm{~mm}$ in diameter (5 $\mathrm{mm}$ thick) magnetron cathode assembly is fixed at the center of the top flange of the chamber. A substrate holder (anode) is mounted facing the cathode assembly and kept at a constant distance of $4 \mathrm{~cm}$. The electrical circuit diagram of supported discharge is shown in Fig. 1b. The supported discharge assembly consisting of a tungsten filament mounted onto two low tension (LT) electrodes is attached to the flange. This flange is fixed into a double walled water cooled cylindrical port mounted horizontally to the chamber wall. In order to sustain the discharge, the filament is heated to emission temperatures by passing AC current. A negative DC voltage superimposed onto the electrodes repels the emitted electrons away from the filament. These electrons during their travel away from the filament undergo collisions with the background gases which results in ionization. This creates the additional ions available to sputtering the target in addition to the ions generated during collisions with secondary electrons emitted from the target. This system may also

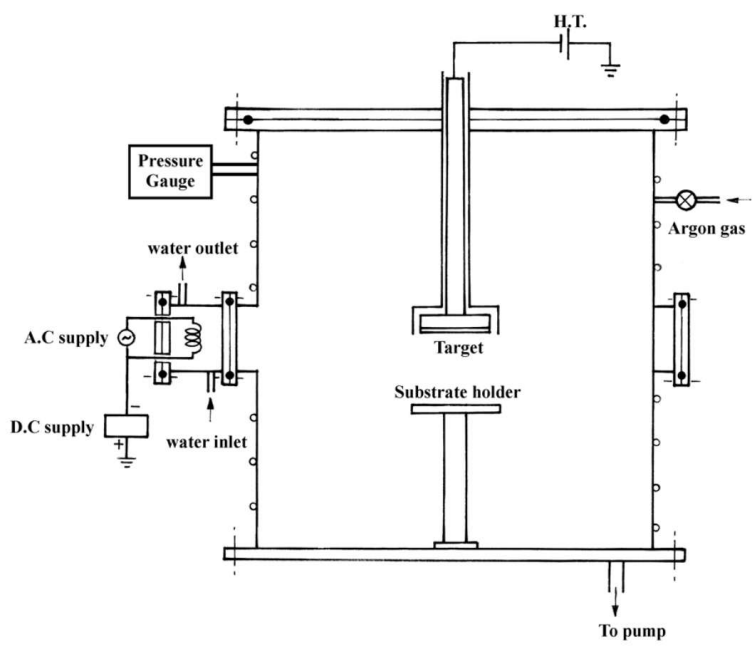

(a)

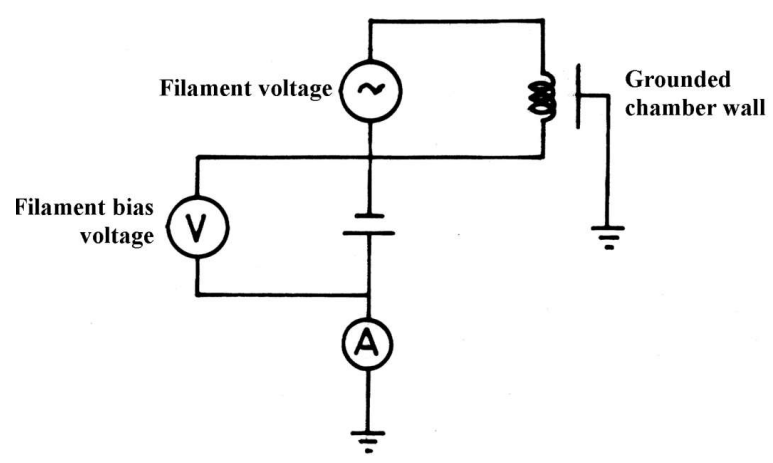

(b)

Fig. 1. (a) schematic diagram of DC magnetron sputtering with supported discharge, (b) electrical circuit diagram of the supported discharge.

be adapted to the conventional DC sputtering by switching off the power given to filament.

The discharge characteristics (filament bias current/discharge current in the chamber) were studied at different argon gas pressures $(0.5,0.7,0.8$ and $1 \mathrm{~Pa}$, by keeping the filament AC heating voltage constant $(14 \mathrm{~V})$ and at different filament DC bias voltages $(10 \mathrm{~V}, 20 \mathrm{~V}, 30 \mathrm{~V}, 40 \mathrm{~V}, 50 \mathrm{~V}$, and $60 \mathrm{~V})$. The influence of filament bias current/discharge current on the current at sputtering target was measured to evaluate the system performance at different DC target voltages $(400 \mathrm{~V}, 500 \mathrm{~V}, 600 \mathrm{~V}, 700 \mathrm{~V}$, $800 \mathrm{~V}$, and $900 \mathrm{~V})$. Different voltages were applied to the magnetron target (titanium disc) to observe the effect of discharge current at the target. 
In order to study the discharge behavior, the chamber was first evacuated to a base pressure of $5 \times 10^{-4} \mathrm{~Pa}$. Argon gas was introduced into the chamber to achieve the earlier assumed pressure values. Then, at $14 \mathrm{~V}$ AC voltage on the filament, the bias voltages were varied and the resulting filament bias currents/discharge current $(0.2 \mathrm{~A}, 0.4 \mathrm{~A}$, $0.6 \mathrm{~A}, 0.8 \mathrm{~A}$ and $1.0 \mathrm{~A})$ were noted. The experiment was repeated for different pressures and filament voltages. After studying the discharge characteristics at different discharge currents, different voltages were applied to the magnetron target to observe the effect of discharge current at the target.

\section{Characterization techniques}

The crystal structure of the Ti thin films was studied using Philips PAN analytical X-ray diffractometer with $\operatorname{CuK} \alpha(\lambda=1.541 \AA)$ radiation. The thickness of the as-prepared Ti thin films was measured using a stylus profilometer. The sheet resistance was measured with a standard two-probe instrument. Elemental analysis was performed with EDAX (TSL AMETEK Make) using FESEM (FEI Quanta 200). The surface topography and surface roughness of $\mathrm{Ti}$ thin films were investigated using atomic force microscope (Model-A 100 AFM) over an area of $1 \mu \mathrm{m} \times 1 \mu \mathrm{m}$.

\section{Results and discussion}

\subsection{Characteristics of the supported dis- charge system}

A typical voltage-current relationship in diode and triode modes is shown in Fig. 2. It can be observed that it is possible to control the target current for a given target voltage by varying the filament bias current. This is because of the availability of sufficient number of ions in the chamber due to the discharge sustained by the biased-thermionic filament. Similar effect on the target current for different target voltages at a constant filament bias current of 1.0 A for different pressures has been shown in Fig. 3. An increase in target current with a decrease in pressure, in the triode discharge system is observed, which has also been noticed by other researchers, Gunasekhar et al. [14] and Swarnalatha et al. [17]. The range of pressure in which the current increases followed by its decrease is dependent on the location of the thermionic filament source and target with respect to each other. From the figure, it is possible to control the target current independently of pressure by varying the target voltage. The observed data also show that it is possible to sputter the deposited films at much lower argon pressure in the supported discharge system compared to that operating in diode mode, where the discharge could not be sustained. It is also possible to control the target voltage, target current and pressure independently of one another, unlike in diode discharge, where they are mutually dependent. For depositions at a lower pressure, the sputtered atoms undergo lesser number of collisions before reaching the substrate. This in turn, could result in higher number of atoms reaching the substrate at relatively higher energies due to which the physical properties, such as structure and microstructure of the deposited films are likely to be altered.

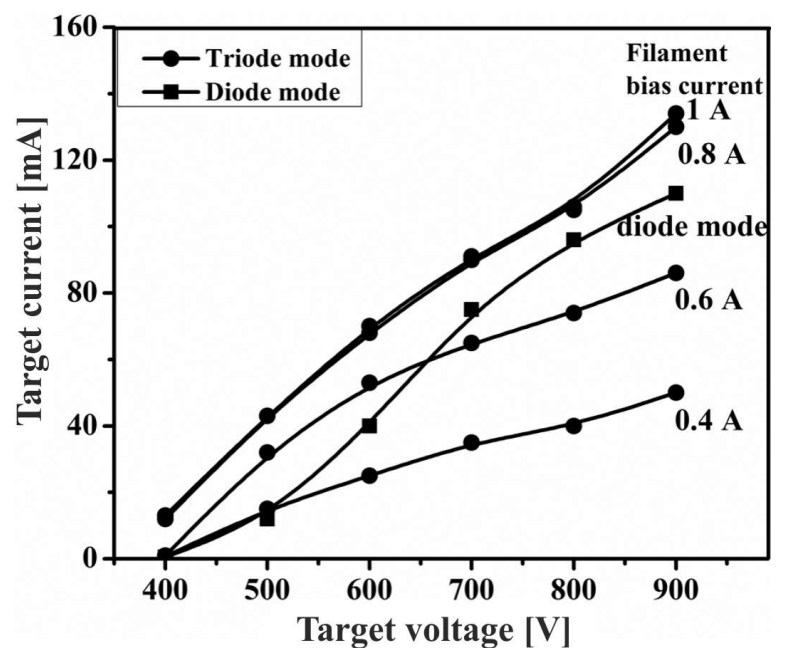

Fig. 2. Voltage-current characteristics in diode mode and triode mode at different filament bias currents.

\subsection{Physical properties of the titanium films}

Pre-cleaned substrates (Si wafers) were loaded into the vacuum chamber and the chamber was 


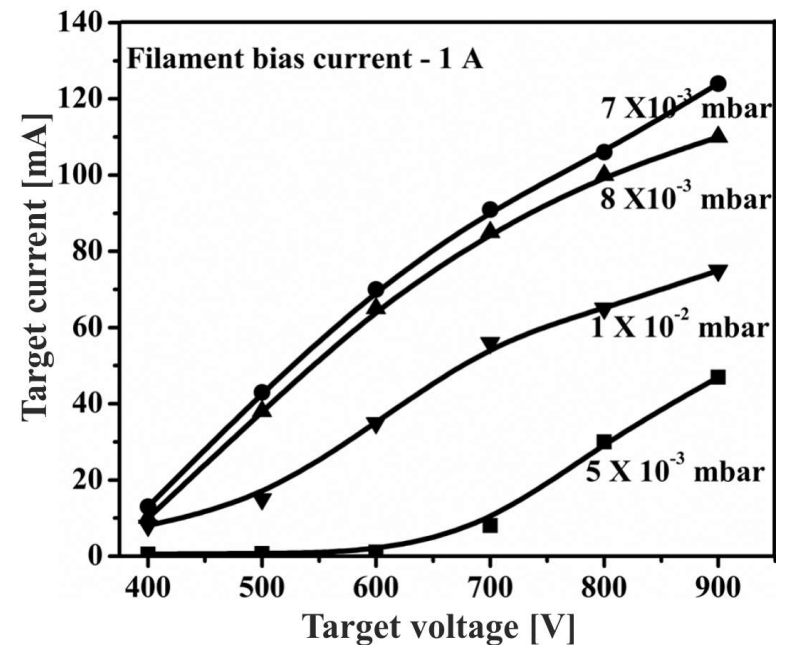

Fig. 3. Variation of target current with target voltage at a constant filament bias current of 1.0 A for different pressures.

evacuated to a base vacuum of $4 \times 10^{-4} \mathrm{~Pa}$. High purity argon gas $(99.99 \%)$ was admitted into the vacuum chamber through a fine controlled needle valve and the chamber pressure was maintained at 0.7 Pa to sustain the discharge. Titanium thin films deposition was carried out at different target powers $(60 \mathrm{~W}, 80 \mathrm{~W}, 100 \mathrm{~W}$ and $120 \mathrm{~W})$ in triode mode for $20 \mathrm{~min}$. The applied AC voltage across the filament was maintained at $14 \mathrm{~V}$, resulting in $13 \mathrm{~A}$ current through the thermionic filament. The negative DC voltage was maintained at $-25 \mathrm{~V}$ to sustain a discharge current of 1.0 A. The details are shown Fig. 1b. Keeping all other parameters the same as in triode mode, Ti thin films were deposited in diode mode (pressure of $3 \mathrm{~Pa}$ ) with varying target power $(60 \mathrm{~W}$ to $120 \mathrm{~W})$. The films deposited both in diode and triode modes were studied in terms of composition as well as structural/morphological and electrical properties.

\subsubsection{Rate of deposition and elemental compo- sition}

Fig. 4. shows the dependence of thickness/rate of deposition on target power for the films deposited in diode (at $3 \mathrm{~Pa}$ ) and supported discharge (at $0.7 \mathrm{~Pa}$ ) modes. The relationship between sputtering pressure and mean free path $(\lambda)$ is governed by the relation [18]:

$$
\lambda=2.330 \times 10^{-18} T /\left(P \delta_{m}^{2}\right)
$$

where $\mathrm{T}$ is the room temperature in $[\mathrm{K}], \mathrm{P}$ is argon sputtering pressure in $[\mathrm{Pa}]$ and $\delta_{\mathrm{m}}$ is the molecular diameter in $[\mathrm{cm}]$. From the above equation, when sputtering pressure is high, the mean free path is short; the sputtered atoms undergo higher number of collisions resulting in loss of sputtered atoms due to scattering. Hence, lesser number of atoms arrives at the substrate. At lower pressure the mean free path is relatively high, so the number of collisions decreases and the number of atoms reaching the substrate is high. As a result it is possible to achieve higher thicknesses with decreasing pressure for a given target power [19].

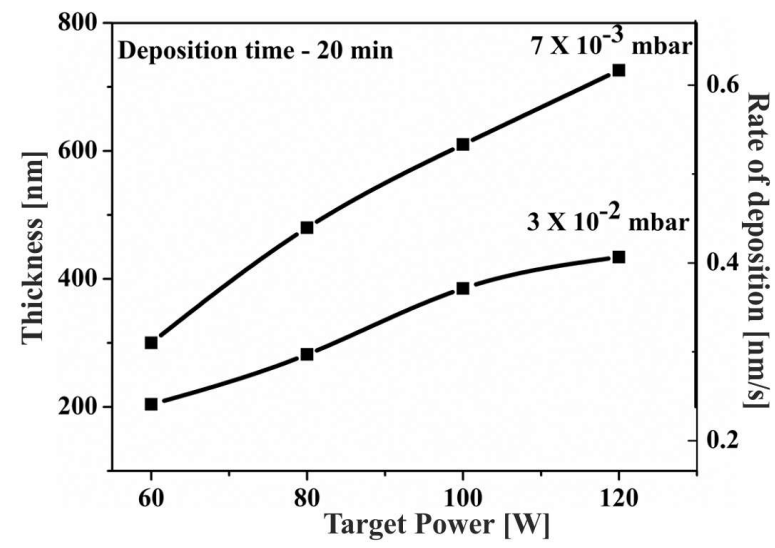

Fig. 4. Variation of thickness/rate of deposition on target power for the films deposited in diode and supported discharge modes, for $\mathrm{d}_{\mathrm{S}-\mathrm{T}}=4 \mathrm{~cm}$.

Typical EDAX spectra for the Ti films deposited at an argon partial pressure of $3 \mathrm{~Pa}$ in diode mode and at $0.7 \mathrm{~Pa}$ in supported discharge mode at target power of $120 \mathrm{~W}$ have been shown in Fig. 5. From the spectra it is clear that the films deposited at lower pressures in supported discharge mode have better purity. The reason for obtaining relatively pure films is probably caused by lesser incorporation of background gases into the film at higher incident rate of the sputtered atoms as well as lesser interaction collisions with residual reactive gases in the chamber due to longer mean free path before reaching the substrate. 


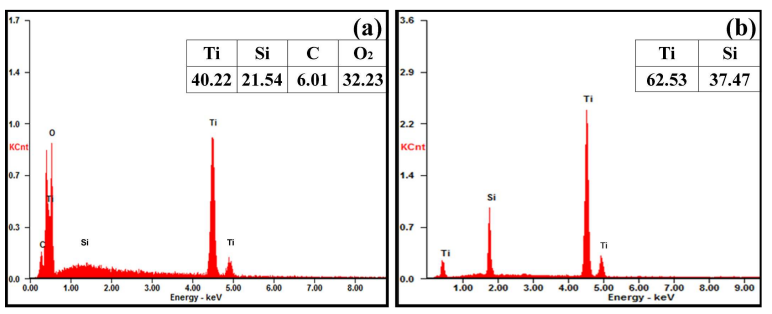

Fig. 5. EDS spectra for the Ti thin films deposited at (a) $3 \mathrm{~Pa}$ and (b) $0.7 \mathrm{~Pa}$.

\subsubsection{Structural analysis}

Structural variations of $\mathrm{Ti}$ films deposited in diode mode at a pressure of $3 \mathrm{~Pa}$ and in supported discharge mode at a pressure of $0.7 \mathrm{~Pa}$ at different powers are shown in Fig. 6a and Fig. 6b, respectively. From Fig. 6a, the films deposited at a power up to $100 \mathrm{~W}$ do not show any crystallinity. Only at a power of $120 \mathrm{~W}$ the films show crystallinity with preferred orientations of (lllll $\left.\begin{array}{lll}1 & 0\end{array}\right)$ and $\left(\begin{array}{lll}0 & 0 & 2\end{array}\right)$. In the films deposited at lower pressure of $0.7 \mathrm{~Pa}$ with supported discharge, the onset of crystallinity starts at the power of $80 \mathrm{~W}$ with a preferred orientation of $\left(\begin{array}{lll}0 & 0 & 2\end{array}\right)$, while no crystallinity has been observed in the films prepared at $60 \mathrm{~W}$. Further increase in power to $100 \mathrm{~W}$ resulted in another preferred orientations of (lllll 100 along with $\left(\begin{array}{lll}0 & 0 & 2\end{array}\right)$. At a power of $120 \mathrm{~W}$, the intensity of the peaks increased with the appearance of (lllll 01 ) peak [20]. Similar results were obtained by Chawla et al. [9] who prepared Ti thin films by DC magnetron sputtering at substrate temperature of $200{ }^{\circ} \mathrm{C}$. Junga et al. [3] deposited Ti thin films with grid-attached magnetron sputtering in which the substrate bias of $150 \mathrm{~V}$ was applied. Fontana et al. [1] prepared Ti thin films by triode magnetron sputtering at substrate temperature of $100{ }^{\circ} \mathrm{C}$ and substrate bias of $300 \mathrm{~V}$. Golan et al. [13] deposited Ti thin films using triode sputtering by biasing the substrate and at substrate temperature of $50{ }^{\circ} \mathrm{C}$.

Both, the target power and working gas pressure have a great influence on crystallinity of the growing film. The increase in target power for a given pressure results in an increase of the plasma density and hence, higher Ar ion density at the target surface. As a result more titanium atoms get sputtered. This leads to an increase in film

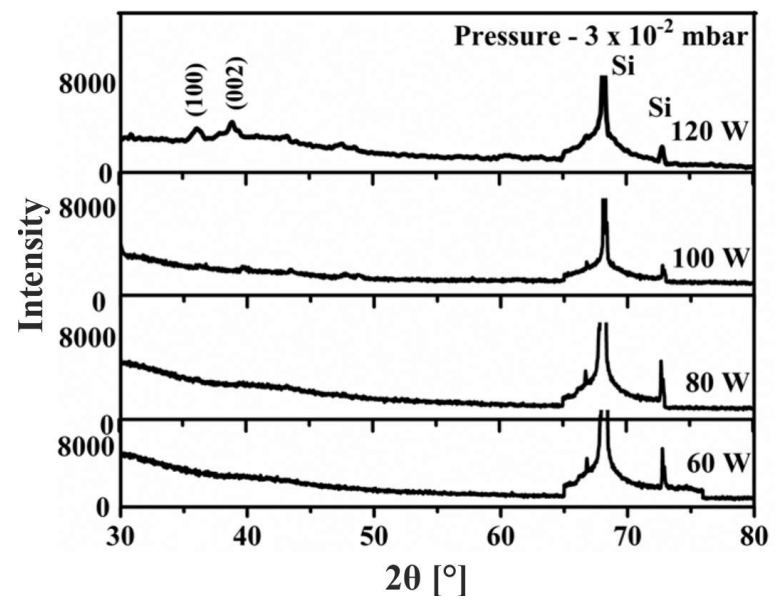

(a)

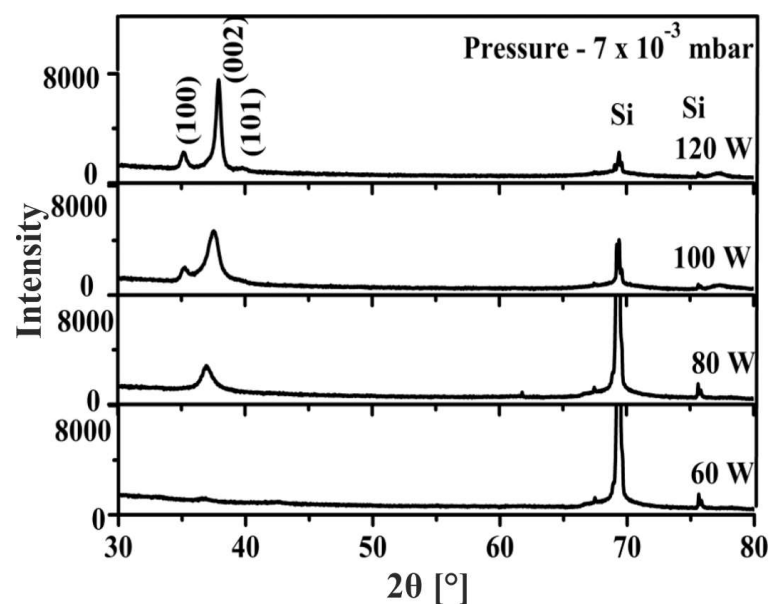

(b)

Fig. 6. XRD patterns of Ti thin films deposited at a pressure of (a) $3 \mathrm{~Pa}$, (b) $0.7 \mathrm{~Pa}$ at different target powers.

deposition rate. With increasing target power, the substrate will also be subjected to a more energetic electron/ion interaction. At low sputtering pressure $(0.7 \mathrm{~Pa})$, the mean free path of $\mathrm{Ti}$ atoms travelling through Ar gas is of the same order as the targetsubstrate distance. In this case, they can reach the growing surface without losing energy due to lesser number of gas collisions. In addition, ionization of $\mathrm{Ti}$ and Ar occurs due to electrons emitted by the thermionic filament. This results in higher energy of Ti atoms/ions reaching the substrate, which leads to improved crystallinity of the films. These effects might account for the observed changes in the crystallinity. Similar observations were made by other 
reserachers [21, 22]. However, as the pressure is increased, both the electron temperature and the electron density decrease. At higher argon pressure (3 Pa) it may not be possible because the plasma is confined very close to the target surface and the effect of plasma can be reduced at the substrate surface.

The qualitative analysis of particle size and relative intensity is shown in Table 1 . The grain size increases as the target power increases. Movchan et al. [23] and Thornton [24] reported an increase in the crystal size with an increase in temperature. Our present studies indicate an increase in crystal size with increasing the target power. Hence, the effect of increasing target power and reduced gas pressure is similar to that of increasing the substrate temperature.
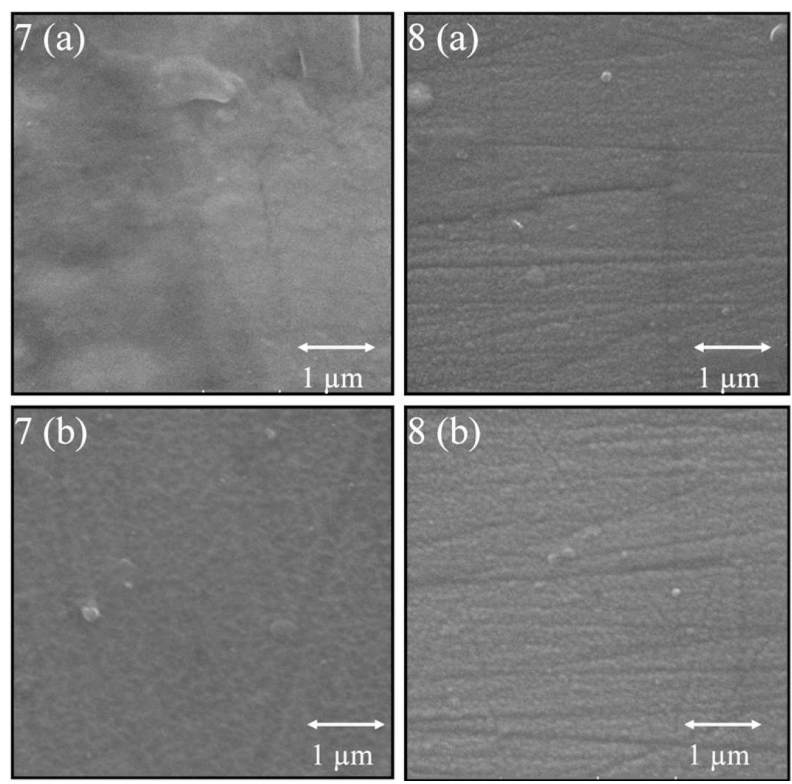

Fig. 7. SEM images of Ti thin films deposited in diode mode at the target power of (a) $60 \mathrm{~W}$, (b) $80 \mathrm{~W}$, (c) $100 \mathrm{~W}$ and (d) $120 \mathrm{~W}$.

\subsubsection{Microstructure analysis}

The SEM photographs of Ti thin films deposited at the pressures of $3 \mathrm{~Pa}$ and $0.7 \mathrm{~Pa}$ at different target powers $(60 \mathrm{~W}$ to $120 \mathrm{~W})$ are shown in Fig. 7 and Fig. 8. The film deposited in diode modes has smaller grains as compared to the films deposited at $0.7 \mathrm{~Pa}$, in triode mode. A very smooth
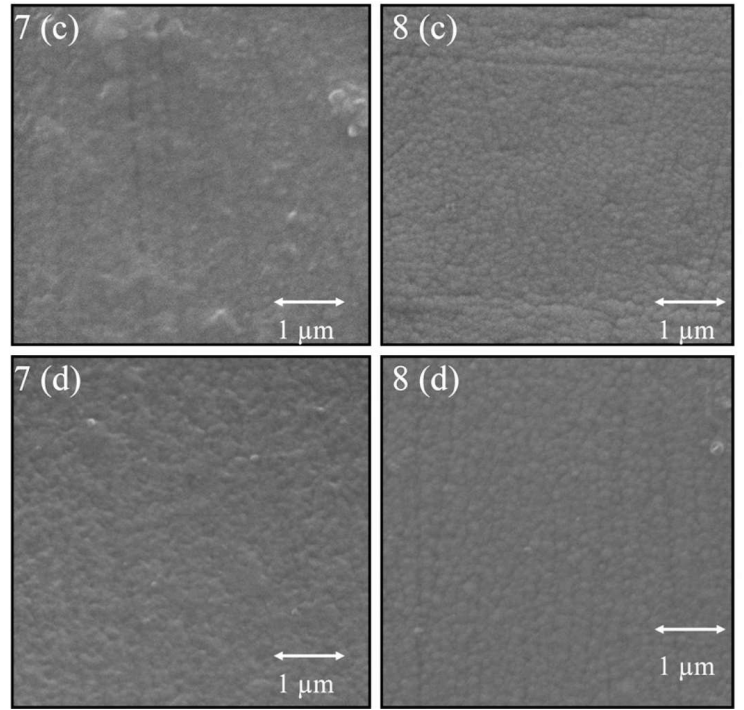

Fig. 8. Ti thin films deposited in triode mode at the target power of (a) $60 \mathrm{~W}$, (b) $80 \mathrm{~W}$, (c) $100 \mathrm{~W}$ and (d) $120 \mathrm{~W}$.



Fig. 9. AFM images of Ti films deposited in supported discharge system at the target power of (a) $60 \mathrm{~W}$, (b) $80 \mathrm{~W}$, (c) $100 \mathrm{~W}$ and (d) $120 \mathrm{~W}$.

surface with larger grains has been observed in triode mode. The films deposited at both triode and diode modes show an increase in the grain size with an increase in target power. The microstructure of the Ti coating is directly influenced by kinetic energy (i.e. surface mobility) of the titanium atoms reaching the substrate. Hence, 
Table 1. Qualitative analysis of crystallite size.

\begin{tabular}{ccccc}
\hline $\begin{array}{c}\text { Working } \\
\text { pressure [Pa] }\end{array}$ & $\begin{array}{c}\text { Target } \\
\text { power [W] }\end{array}$ & $\begin{array}{c}\text { Grain } \\
\text { size [nm] }\end{array}$ & $\begin{array}{c}\text { Relative } \\
\text { intensity [\%] }\end{array}$ & $\begin{array}{c}\text { Surface } \\
\text { roughness [nm] }\end{array}$ \\
\hline \hline \multirow{2}{*}{0.7} & 80 & 64 & 36 & 7 \\
& 100 & 65 & 62 & 12 \\
& 120 & 80 & 100 & 15 \\
\hline 3 & 80 & 12 & 8 & 2 \\
& 100 & 13 & 9 & 4 \\
& 120 & 20 & 12 & 5 \\
\hline
\end{tabular}

an important parameter to be considered is vapor flux arriving at the substrate. At the higher pressure $(3 \mathrm{~Pa})$, the amount of thermalized flux increases and fewer energetic titanium atoms reach the substrate. At the highest gas pressure, the finegrained structure is more porous, since the lowest kinetic energy is achieved under these conditions [25]. This can be confirmed by the SEM image shown in Fig. 8. At lower working pressure $(0.7 \mathrm{~Pa})$, the mean free path increases and the number of collisions is reduced before reaching the substrate. As a result, the sputtered $\mathrm{Ti}$ atoms grow into larger grains with different crystal orientations having fine rounded edges, which can be confirmed by AFM as shown Fig. 9d. Fig. 9 shows the Ti thin films deposited at different target powers with supported discharge. The film deposited at lower target power exhibits smooth surface without any pits and pinholes over the surface. Higher target power with a lower working pressure resulted in the large agglomerates with bigger grains. The AFM images show an increase in surface roughness values from $3 \mathrm{~nm}$ to $15 \mathrm{~nm}$ with an increase in target power.

\subsubsection{Electrical properties}

The electrical resistivity of titanium thin films as a function of target power is shown in Fig. 10. The resistivity decreases as the target power increases from $60 \mathrm{~W}$ to $120 \mathrm{~W}$ for both diode and triode system. There is a large difference in resistivity of the films deposited with and without supported discharge. This can be explained by the difference in crystalline structure and on the basis of Matthiessen's rule. The Ti thin film prepared in diode mode has an amorphous structure with smaller grains. According to Igasaki et al. [26], when the grain size is smaller than the mean free path of electrons, the scattering mechanism causes an increase in the resistivity. The influence of gaseous impurities incorporated during the deposition process as discussed in EDAX also raises the electrical resistivity. The Ti thin films prepared in supported discharge mode have larger grains and lower amount of incorporated impurities, which reduces their electrical resistivity.

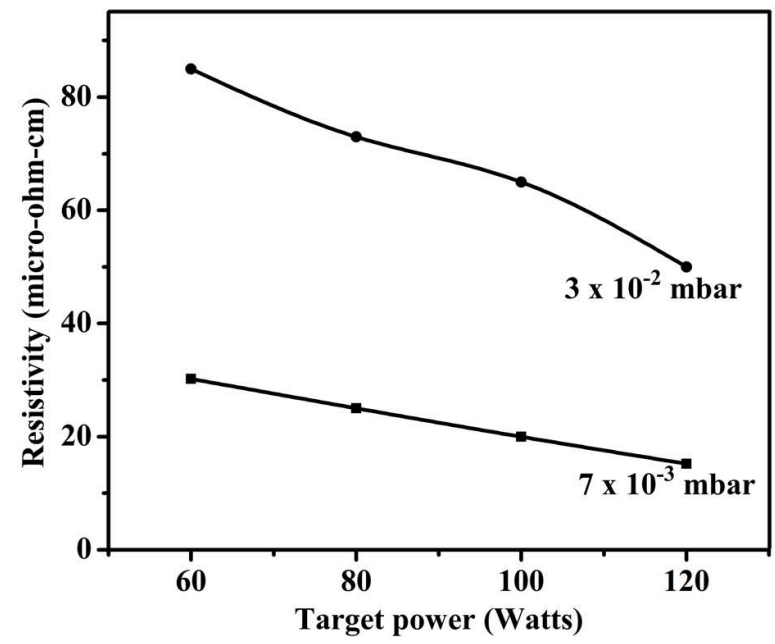

Fig. 10. Variation of electrical resistivity with target power of Ti thin films deposited in diode and triode mode.

\section{Conclusions}

In summary, the supported discharge is more efficient sputtering deposition method compared to the conventional diode magnetron sputtering. 
The supported discharge system enables control of target current independently of operating pressure and target voltage. The influence of target power on the physical properties of the coatings obtained in the supported discharge mode has been studied with respect to the diode system. The supported discharge DC magnetron technique makes possible to achieve the required physical properties of Ti thin films much more efficiently than the other sputtering techniques.

\section{References}

[1] Fontana L.C., MuZart J.L.R., Surf. Coat.Tech., 107 (1998), 24.

[2] Sagas J.C., Fontana L.C., Macielh C., Vacuum, 85 (2011), 705.

[3] Junga M.J., NAma K.H., Shaginyanb L.R., Hana J.G., Thin Solid Films, 435 (2013), 145.

[4] Mattox D.M., Handbook of Physical Vapor Deposition (PVD) Processing, Elsevier, New York, 1998.

[5] Beilis I.I., Shnaiderman A., Boxman R.L., Surf. Coat. Tech., 203 (2008), 501.

[6] Cai K., Muller M., Bossert J., RechtenBACH A., JAndt K.D., Appl. Surf. Sci., 250 (2005), 252.

[7] Kersten H., Steffen H., Vender D., Wagner H.E., Vacuum, 46 (1995), 305.

[8] Chen A.Y., Bua Y., Tanga Y.T., Wang Y., LiUa F., XIE X.F., Gud J.F., Thin Solid Films, 574 (2015), 71.

[9] Chawla V., Jayaganthana R., Chawla A.K., Chandra R., Mater. Chem. Phys., 111 (2008), 414.

[10] LiU Y.-L., LiU F., Wu Q., Chen A.-Y., Xiang L.I., Pan D., T. Nonferr. Metal. Soc., 24 (2014), 2870.

[11] Bharathy V.P., Nataraj D., Chub P.K., WANG H., YANG Q., KIRAN M.S.R.N., ALBeroej S., Raja M.D., Appl. Surf. Sci., 257 (2010), 143.
[12] Gunasekhar K.R., Srinivasulu S., Swarnalatha M., Ghanashyam Krishna M., MoHAN S., Thin Solid Films, 252 (1994), 7.

[13] Golan G., Axelevitch A., Microelectron. J., 33 (2002), 651.

[14] Gunasekhar K.R., Mohan S., Vacuum, 42 (1991), 661.

[15] Matthews A.,Teer D.G., Thin Solid Films, 72 (1980), 541.

[16] Salmenoj A.K., Molarius J.M., Korhonen A.S., Thin Solid Films, 155 (1987), 143.

[17] Swarnalatha M., Sravani C., Gunasekhar K.R., Muralidhar G.K., Mohan S., Vacuum., 48 (1997), 845.

[18] Chawla V., Jayaganthan R., Chawla A.K., Chandra R., J. Mater. Process. Tech., 209 (2009), 3444.

[19] Jin Y., WU W., Li L., Chen J., Zhang J., Zuo Y., FU J., Appl. Surf. Sci., 255 (2009), 4673.

[20] Rawala S.K., Chawla A.K., Jayaganthan R., Chandra R., B Mater. Sci., 36 (2013), 403.

[21] LU Y.M., Hwang W.S., LiU W.Y., YANG J.S., Mater. Chem. Phys., 72 (2001), 269.

[22] Andujar J.L., Pino F.L., Polo M.C., Pinyol A., Corbella C., Bertran E., Diam. Relat. Mater., 11 (2002), 1005.

[23] Movchan B.A., Demchishin A.V., FIZIKA, Metalloved, 28 (1969), 653.

[24] Thornton J.A., J. Vac. Sci. Technol., 11 (1974), 666.

[25] Avelar-Batista J.C., Wilson A.D., Davison A., Matthews A., FAnCEYA K.S., Vacuum, 72 (2004), 225.

[26] Igasaki Y., Mitsuhasi H., Thin Solid Films, 51 (1978), 33. 